\title{
Shaw, Frank, Fournier, Johannes, Gärtner, Kurt, Die Weltchronik von Heinrich von München. Neue Ee
}

\section{Mathieu Olivier}

\section{OpenEdition}

\section{Journals}

Édition électronique

URL : http://journals.openedition.org/ifha/2149

DOI : $10.4000 /$ ifha. 2149

ISSN : 2198-8943

Éditeur

IFRA - Institut franco-allemand (sciences historiques et sociales)

Référence électronique

Mathieu Olivier, «Shaw, Frank, Fournier, Johannes, Gärtner, Kurt, Die Weltchronik von Heinrich von München. Neue Ee », Revue de l'IFHA [En ligne], Date de recension, mis en ligne le 01 janvier 2010 consulté le 22 septembre 2020. URL : http://journals.openedition.org/ifha/2149 ; DOI : https://doi.org/ $10.4000 /$ ifha. 2149

Ce document a été généré automatiquement le 22 septembre 2020.

(C)IFHA 


\title{
Shaw, Frank, Fournier, Johannes, Gärtner, Kurt, Die Weltchronik von Heinrich von München. Neue Ee
}

\author{
Mathieu Olivier
}

1 La chronique universelle rimée de " Heinrich von München » appartient à côté de l'œuvre d'un Rudolf von Ems ou d'un Jans Enikel, aux fleurons d'un genre, la chronique universelle rimée, qui connut, dans l'Empire médiéval, une fortune considérable. Compilation largement appuyée sur ses devancières, elle se situe, dans la seconde moitié du XIVe siècle, au débouché d'une tradition dont l'âge d'or se situe au XIIIe siècle. C'est du reste à cette rédaction tardive - plus tardive assurément qu'on ne l'a longtemps cru - qu'il convient d'imputer, pour une large part, le relatif désintérêt dont la chronique de « Henrich de München » a longtemps pâti dans la Altgermanistik.

2 La présente édition de texte, œuvre collective de longue haleine coordonnée par F.S., J.F. et K.G., prolonge et couronne la vaste entreprise philologique entamée à la fin des années 1980 sur ce texte protéiforme et assez insaisissable en dépit - ou à cause - d'une tradition très dense. Elle procède en outre d'un double choix que l'auteur de ces lignes salue, mais dont les motivations, parfois critiquées, méritent d'être explicitées. Choix, en premier lieu, d'éditer la partie du texte qui se trouve être à la fois la moins connue et aussi la moins stable dans la tradition, l'histoire de l'ère chrétienne depuis la naissance du Christ jusqu'au début du XIIIe siècle (Neue Ee) - pour les versions les plus complètes ; l'édition prend le contrepied d'une Altgermanistik qui, par le passé, s'est sutout attachée à l'Alte Ee. Choix, par ailleurs, d'une édition complète du texte, alors que la compilation s'appuie sur des sources presque entièrement identifiables et connues, voire procède par emprunts massifs et fidèles à ces mêmes sources.

3 Si le présent volume réjouira en première ligne le spécialiste de langue et de littérature, l'historien de l'historiographie et celui des mentalités nobiliaires y trouveront également leur compte. Sans doute élaboré en plusieurs étapes dans le sud de l'Empire pour un public nobiliaire et en fonction de ses goûts, ce vaste ensemble nous offre un observatoire intéressant d'où observer, à la fin du XIVe siècle, ce que savait et attendait 
ce public de l'Histoire sainte en général et du récit de la Passion en particulier, mais aussi des temps carolingiens ou de la trajectoire des Staufen.

4 Mathieu Olivier (Lycée Dumont-d’Urville, Toulon) 